\title{
Associations between the organisation of stroke services, process of care, and mortality in England: prospective cohort study
}

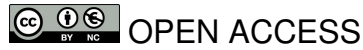

\author{
Benjamin D Bray clinical academic fellow ${ }^{1}$, Salma Ayis lecturer in medical statistics ${ }^{14}$, James \\ Campbell stroke audit development manager ${ }^{2}$, Alex Hoffman stroke programme manager ${ }^{2}$, Michael \\ Roughton medical statistician ${ }^{2}$, Pippa J Tyrrell professor of stroke medicine ${ }^{3}$, Charles D A Wolfe \\ professor of public health medicine ${ }^{14}$, Anthony G Rudd professor of stroke medicine ${ }^{14}$
}

${ }^{1}$ King's College London, Division of Health and Social Care Research, London SE13QD, UK; ${ }^{2}$ Royal College of Physicians, London, UK; ${ }^{3}$ University of Manchester MAHSC, Salford Royal NHS Foundation Trust, Salford, UK; ${ }^{4}$ National Institute for Health Research Comprehensive Biomedical Research Centre, Guy's and St Thomas' NHS Foundation Trust, London, UK

\begin{abstract}
Objective To estimate the relations between the organisation of stroke services, process measures of care quality, and 30 day mortality in patients admitted with acute ischaemic stroke.

Design Prospective cohort study.

Setting Hospitals ( $n=106$ ) admitting patients with acute stroke in England and participating in the Stroke Improvement National Audit Programme and 2010 Sentinel Stroke Audit.

Participants 36197 adults admitted with acute ischaemic stroke to a participating hospital from 1 April 2010 to 30 November 2011.

Main outcome measure Associations between process of care (the assessments, interventions, and treatments that patients receive) and 30 day all cause mortality, adjusting for patient level characteristics.

Process of care was measured using six individual measures of stroke care and summarised into an overall quality score.

Results Of 36197 patients admitted with acute ischaemic stroke, 25 $904(71.6 \%)$ were eligible to receive all six care processes. Patients admitted to stroke services with high organisational scores were more likely to receive most ( 5 or 6 ) of the six care processes. Three of the individual processes were associated with reduced mortality, including two care bundles: review by a stroke consultant within 24 hours of admission (adjusted odds ratio $0.86,95 \%$ confidence interval 0.78 to 0.96 ), nutrition screening and formal swallow assessment within 72 hours $(0.83,0.72$ to 0.96$)$, and antiplatelet therapy and adequate fluid and nutrition for first the 72 hours $(0.55,0.49$ to 0.61$)$. Receipt of five or six care processes was associated with lower mortality compared with
\end{abstract}

receipt of $0-4$ in both multilevel $(0.74,0.66$ to 0.83$)$ and instrumental variable analyses $(0.62,0.46$ to 0.83$)$.

Conclusions Patients admitted to stroke services with higher levels of organisation are more likely to receive high quality care as measured by audited process measures of acute stroke care. Those patients receiving high quality care have a reduced risk of death in the 30 days after stroke, adjusting for patient characteristics and controlling for selection bias.

\section{Introduction}

Stroke is a leading cause of death and disability, with an estimated annual incidence of 110000 in the United Kingdom. ${ }^{1}$ Evidence from controlled trials shows the effectiveness of a variety of interventions for acute stroke, ${ }^{2}$ including thrombolysis with recombinant tissue plasminogen activator, ${ }^{34}$ stroke unit based care, ${ }^{5}$ secondary prevention, ${ }^{67}$ and early supported discharge. ${ }^{8}$ Measuring the achievement of processes of care (the interventions, assessments, and treatments that patients receive) through clinical audit is used in health systems around the world for quality improvement, performance management, and financial reimbursement. ${ }^{910}$ Across England, Wales, and Northern Ireland, the Royal College of Physicians stroke programme has been carrying out systematic audits of the quality of stroke care since 1998. ${ }^{11}$ The audit of stroke care has largely focused on process measures of quality such as access to thrombolysis or admission to stroke units. ${ }^{10}$ Process measures have several advantages over direct measures of patient 
outcomes, including greater sensitivity and responsiveness to intervention; outcome measures such as mortality may be confounded by variations in case mix or demographics and may be more susceptible to measurement and coding error. ${ }^{12}{ }^{13}$ However, the validity of process measures rests on the assumption that they are a useful proxy of subsequent outcomes and that the interventions being measured produce the expected effects. Even interventions shown to be effective in clinical trials may not produce the predicted effects in the "real world"-for example, results may be distorted by publication bias or not be applicable beyond the population included in the trial. In the case of quality measures for stroke, the quality and methodological limitations of previous studies has resulted in only limited evidence for the validity of process measures of stroke quality. ${ }^{14}$

We estimated the relation between individual process measures for the quality of acute stroke care and an overall composite "quality score" with 30 day mortality using data collected through two national clinical audits, the Stroke Improvement National Audit Programme (SINAP) and the National Sentinel Stroke Audit. Because these are observational data with the potential for indication bias, we used several strategies to reduce the effects of confounding, including a quasi-experimental instrumental variable technique.

\section{Methods}

\section{Data collection}

Figure $1 \Downarrow$ summarises the study design. Data were collected as part of the Stroke Improvement National Audit Programme, which is a prospective national audit of the first 72 hours of stroke care in England. The audit is managed by the Royal College of Physicians of London and was established in 2010 to describe the quality of care afforded to patients with acute stroke. Data on consecutive patients admitted to acute hospitals are abstracted from local care records and prospectively submitted to the audit via a secure web based tool. The web tool includes real time data validation checks, and records of individual episodes of care cannot be submitted to the audit until all data fields are completed. The audit data were linked using the National Health Service number to hospital episode statistics data (a nationally collected dataset of hospital activity) and to a national register of death notifications. ${ }^{15}$ A secure third party (The NHS Information Centre for Health and Social Care) carried out data linkage and provided the investigators with an anonymised dataset for the analysis.

The quality of care that patients with stroke receive is measured in the Stroke Improvement National Audit Programme through the achievement of 12 process measures (key indicators in the audit's nomenclature). Patients-for example, those who are unconscious, receiving end of life care, or medically unfit (and other prespecified exclusion criteria) - may be identified in the programme as being ineligible for audit measures by the clinical team providing care for them and thus be excluded from the denominator population for the measure. In this study we evaluated process measures that would be applicable to most patients with ischaemic stroke and which described an active treatment or intervention (table $1 \Downarrow$ ). We therefore did not include indicators that applied to fewer than $80 \%$ of patients (on this basis we excluded thrombolysis if eligible, continence plan drawn up within 72 hours if applicable, and arrival on stroke bed within four hours of admission if out of normal hours). We also did not include one measure of data quality (known time of onset for stroke symptoms) and one relating to the quality of communication (prognosis or diagnosis discussed with relative or carer within 72 hours where applicable). Of the two similar indicators related to brain scanning, we excluded one (brain scan within one hour of admission) to avoid duplication. Four of the process measures are care bundles, where all components of the bundle need to be completed for the achievement of the process measure. To assess the relation between overall care quality and mortality we calculated a composite quality score: the cumulative number of the six process measures completed. To reduce the effect of indication bias, we calculated the score only for patients applicable for all six measures. We dichotomised the quality score (range $0-6$ ), with the groupings determined so as to ensure as equal as possible numbers in the two groups: low, 0-4 of six process measures completed, and high, five or six process measures completed. Full details of the audit, its dataset, and definitions are available online (www. rcplondon.ac.uk/resources/sinap-latest-results). ${ }^{16}$

The study cohort included all patients aged 18 or more years with acute ischaemic stroke who were admitted between 1 April 2010 and 30 November 2011 to an English hospital participating in the Stroke Improvement National Audit Programme. To reduce the risk of sampling bias from hospitals with incomplete participation in the programme we excluded data on patients from hospitals admitting fewer than 20 patients with acute ischaemic stroke in this period. We classified stroke type by the Oxford Community Stroke Project definition. ${ }^{17}$

\section{Statistical analysis}

We compared the baseline characteristics of patients using standardised differences of means for continuous variables and of proportions for categorical variables. Standardised differences greater than $10 \%$ were considered to indicate evidence of significant imbalance in patient characteristics between groups. ${ }^{18}$

We estimated the associations between process measures of care and 30 day mortality using multilevel multivariable logistic regression models, adjusted for age, sex, independence in activities of daily living before stroke (defined as a modified Rankin scale of 0 or 1 ), requirement for oxygen therapy in the first 24 hours, reduced consciousness in the first 24 hours, arm weakness or sensory impairment, leg weakness or sensory impairment, dysphasia, and hemianopia. Age was included as a continuous variable and we coded other variables as

dichotomous variables. Consciousness is recorded in the Stroke Improvement National Audit Programme dataset on a four point scale: we coded any response below fully conscious as reduced consciousness. The model was specified as a two level multivariable logistic model using random intercepts for each hospital to account for the clustered nature of the data. The final model had good discrimination, with a $\mathrm{C}$ index (area under the curve) of 0.86 , estimated using receiver operator curve analysis. Sensitivity analysis was carried out by excluding patients who either died or received palliative care within the first 72 hours of admission, on the hypothesis that mortality in this group is largely determined by comorbidity or the severity of the acute illness rather than by process of care.

We carried out a secondary analysis using a quasi-experimental instrumental variable technique to tackle the problem of selection bias through unmeasured confounding, which is common in observational data and may lead to incorrect inference about causation. In this instance we hypothesised that variation in care between hospitals can be considered a natural experiment, analogous to a cluster randomised trial where treatment allocation is determined by hospital of admission. As the instrumental variable we used a measure of the organisational quality of stroke services, the acute domain 
organisational score from the 2010 sentinel audit, on the basis of a previous observation of an association between this measure and the quality of care received by patients. ${ }^{11}$ This is a composite score of the staffing (numbers, type, and training level), facilities (for example, provision of continuous physiological monitoring) and service level (for example, access to round the clock emergency imaging and thrombolysis) of each stroke service in England. The analysis uses this correlation to estimate the odds of 30 day mortality from the predicted quality score of patients, conditional on stroke service organisational score. The instrumental analysis was carried out using biprobit structural equation models and adjusted for the same patient level variables as described for the multilevel models. A more detailed description of the instrumental variable methodology, and in particular the various assumptions of this technique, is provided in the supplementary file.

A two tailed significance level of 0.05 was used in all hypothesis tests. We carried out all analyses using Stata 12MP (Statacorp).

\section{Results}

Data were obtained for 36197 adults admitted with acute ischaemic stroke to the 106 hospitals admitting 20 or more patients during the study period (62\% of eligible hospitals in England). Following data linkage, vital status at 30 days after admission was unavailable for 160 patients $(0.44 \%)$, and so the final mortality models included data for 36037 patients. Table $2 \Downarrow$ shows the characteristics of the cohort. Most $(29561,81.7 \%)$ of the patients were admitted to a stroke unit within 24 hours of admission and $92.4 \%$ (26 981) were admitted by 72 hours. Completion of the six care processes varied considerably: 30 $838(85.2 \%)$ of patients had received a brain scan within 24 hours of admission, whereas only 17990 (52.9\%) were admitted directly to a stroke unit within four hours of admission (table 1). Of the 25904 patients applicable for all six care processes, over half $(13885,53.6 \%)$ received fewer than five.

Table $3 \Downarrow$ shows the association between achievement of these process measures and 30 day mortality. In univariable analyses, all the care processes except bundle 3 (patient's first ward of admission was stroke unit and he or she arrived there within four hours of hospital admission) were associated with reduced mortality. After adjusting for case mix, having a brain scan within 24 hours of admission was not significantly associated with mortality (adjusted odds ratio $0.96,95 \%$ confidence interval 0.86 to 1.07 ). The strongest association with mortality was identified for bundle 4 (patient given antiplatelet therapy where appropriate and adequate fluid and nutrition for first 72 hours), with an adjusted odds ratio of death of 0.46 (95\% confidence interval 0.42 to 0.50 ). Bundle 1 (seen by nurse and one therapist within 24 hours and all relevant therapists within 72 hours) was not significant in a sensitivity analysis that excluded patients dying or receiving palliative care within the first 72 hours; the effect sizes for the other care processes were not meaningfully changed.

Table $4 \Downarrow$ shows the association between quality score and 30 day mortality for patients eligible for all six measures. A high (5 or 6) quality score was associated with a $26 \%$ reduction in the odds of mortality at 30 days after adjustment for case mix (an estimated absolute mortality rate difference of 2.3\%). Again, a similar estimate was observed in the sensitivity analysis.

In the instrumental variable analysis, the 2010 acute domain organisation sentinel stroke audit score satisfied the key assumptions of this technique. Stroke services achieving a higher organisational score provided a greater proportion of patients with the highest levels of care quality. Odds ratios showed a non-linear dose-response relation for the two highest fourths of organisational score: 2.73 (95\% confidence interval 1.43 to 5.19) for the third quarter and 4.63 (2.11 to 10.17) for the fourth quarter, both highly significant (fig $2 \Downarrow$ ). The instrumental variable therefore discriminated well between high and low scoring stroke services but not between middle and low scoring services. Table $5 \Downarrow$ shows that covariate imbalance was much less for the organisational score than it was for the quality score. In addition, no significant associations were found between organisational score and mortality when controlling for quality score (table $6 \Downarrow$, also see supplementary file table 1 ). Using the instrumental variable approach to estimate the association between quality score and mortality, high quality care was found to be associated with a reduced odds of death (adjusted odds ratio $0.62,95 \%$ confidence interval 0.46 to 0.83 , table 4 ).

\section{Discussion}

These analyses show the associations between the organisation of stroke services, process of care, and mortality outcomes in patients with acute ischaemic stroke. Patients admitted to stroke services scoring highly on a measure of organisational quality were more likely to receive all six of the care processes measured in this study. After excluding patients identified by their clinical team as being ineligible to receive all six care processes (for example, because of illness severity or poor prognosis), patients receiving the most complete care had a reduced risk of death in the 30 days after stroke. In addition, by considering variation in care between stroke services as a type of natural experiment, we used an instrumental variable technique to provide supporting evidence that the association between overall quality and mortality may be causal and not merely the result of residual confounding. Although a study of overall stroke care quality is not feasible in a randomised controlled trial, this study suggests that further controlled trials of the individual care bundles measured in this study are warranted. Finally, as well as demonstrating opportunities for quality improvement in stroke care, these results also have implications for the planning and commissioning of stroke services and contribute to broader discussions concerning the use of metrics to measure quality in healthcare.

\section{Comparison with other studies}

How best to measure the quality of care afforded to patients is a question faced in all health systems and is an important health policy question. However, it is not without controversy and in particular there has been much debate about the relative merits of measuring process (the actual care that patients receive) versus direct measures of health outcomes such as mortality. ${ }^{12}{ }^{19-22}$ However, even for processes of care showing effectiveness in controlled trials, it has been surprisingly difficult to demonstrate that the achievement of these processes is correlated with patient outcomes, not just for stroke ${ }^{14}$ but also for a range of other conditions, such as acute myocardial infarction, ${ }^{23}$ heart failure, ${ }^{23}$ pneumonia, ${ }^{23}{ }^{24}$ and high risk surgery. ${ }^{25}$ A recent systematic review found only limited evidence of an association between quality metrics and patient outcomes after stroke, a lack of high quality studies, and several methodological problems with existing studies. ${ }^{14}$ In the only previous study in England, no association was found between process measures of stroke care and hospital level mortality, ${ }^{26}$ although the measures assessed were not the same as those in our study, achievement of the reported measures was lower, and overall 30 day mortality was more than twice as high than in our larger and more recent cohort. 
In this study there was clear evidence that achievement of both individual process measures of stroke care and higher levels of a composite "quality score" were associated with improved mortality outcomes. The reduction in mortality observed for high quality care is broadly equivalent in magnitude to the effect of stroke units as shown in randomised controlled trials and is consistent with the body of evidence demonstrating the benefits of specialised multidisciplinary care for patients with stroke. ${ }^{25}$ Interestingly, despite the established evidence base for stroke units, ${ }^{5}$ in our analysis, failing to be admitted to a stroke unit within four hours of admission was not associated with higher mortality. Possible explanations include improvements in stroke care in clinical areas outside stroke units such that the differential benefit of admission to a stroke unit is less noticeable in contemporary medical practice, or that a delay in admission to a stroke unit does not incur significant mortality risk provided that admission eventually occurs. Indeed, in this cohort, the majority $(92 \%)$ of patients were admitted to a stroke unit within 72 hours. Given the evidence from randomised controlled trials for specialised multidisciplinary care in stroke, ${ }^{5}$ it is possible that the observed benefit of being seen by a stroke consultant within 24 hours is a marker for admission to a stroke unit and multidisciplinary stroke care. This study identified two care bundles that were associated with reduced mortality (nutrition screening and formal swallow assessment within 72 hours where appropriate, and antiplatelet therapy where appropriate and adequate fluid and nutrition for first 72 hours). In the latter bundle, "adequate" fluid was defined conservatively as $\geq 1$ litre/24 hours of enteral or intravenous fluid, but "adequate" nutrition relied on a more subjective assessment from the clinical team of adequacy of nutrition provided via any route (oral, nasogastric, or parenteral). If these associations indeed represent causal relations rather than unmeasured confounding, there are several putative but plausible mechanisms, including the prevention of complications such as aspiration pneumonia or acute kidney injury, and possible effects on cerebral perfusion and metabolism. Previous observational studies have also shown an association of reduced mortality after stroke with nutritional assessment ${ }^{27}$ and swallowing evaluation ${ }^{28}$ and an increased risk of death with dehydration. ${ }^{29}$ A previous cluster randomised trial demonstrated the effectiveness of protocol based management of fever, hyperglycaemia, and swallowing dysfunction,

suggesting that management of physiological variables in acute stroke can improve outcomes. ${ }^{30}$ There are no controlled trials of fluid therapy in acute stroke but the strong signal in these observational data suggests that further studies are warranted.

\section{Methodological considerations}

In this study we developed a novel score to measure the quality of acute stroke care, using six process measures. An alternative three measure score (the organised care index) has also been previously proposed..$^{31}$ In addition to the processes of care directly measured by these scores, the association with mortality might also be mediated through correlations with other unmeasured processes of care. Even if this is the case, scores such as these might be usefully employed to help measure quality improvement in stroke care. One of the principal challenges in understanding the relation between these measures of the quality of the process of care and patient outcomes is indication bias. For example, patients with a worse prognosis may receive different care from patients deemed to have a better prognosis; prognostic factors may therefore confound the relation between process and outcome. This is a challenge not just in observational studies but is also problematic when measuring and reporting on the performance of hospitals, teams, or individual clinicians. Indication bias was clearly present in this cohort: patients with a low quality score were more likely to require oxygen therapy and have impaired consciousness and less likely to be independent before stroke than patients in whom a high quality score was achieved. This study attempted to control for indication bias in three ways: firstly, patients could be identified as being ineligible for each process of care by their clinical team if they were deemed unfit or unable to receive the process of care (for example, a swallow assessment in an unconscious patient). Only patients not identified as being ineligible by their clinical team were subsequently included in the analysis. Secondly, we used multivariable regression to control for patient characteristics that predict risk of mortality, such as age, consciousness level, and premorbid functional status. Finally, we used an instrumental variable method that has the theoretical advantage of being able to control for unmeasured confounding. This instrumental variable methodology has only recently been used in the health sciences literature and we are aware of only one other study making use of this in the stroke specific literature. ${ }^{32}$ The approach has several important limitations, not least the difficulty of identifying a suitable instrumental variable and natural experiment to model. The approach also requires several strong assumptions, as already discussed in this paper. Some of these assumptions are difficult or impossible to test formally, such as the assumption that the association between the instrument and outcome is mediated only via the exposure of interest. None the less, instrumental variable analysis seems to have much potential for improving the ability of observational studies to show causal relations and has recently been endorsed in the draft methodology statement of the Patient Centred Outcomes Research Institute. ${ }^{33}$ The technique may also have potential for developing and validating healthcare performance measures, particularly in instances where controlled studies are likely to be unethical or not feasible. As far as we are aware, this is the first reported use of a measure of health service organisation being used as an instrumental variable, although the triad of structure, process, and outcome is well established in theoretical conceptualisations of healthcare quality, ${ }^{34}$ and it is likely that a similar approach could be used in non-stroke settings.

\section{Strengths and limitations of this study}

This study has several strengths, including a national sampling frame, few missing data, and a large sample size. In addition, we have used methodologies that specifically deal with some of the limitations of previous studies, including statistical techniques to allow for clustered data and the use of an instrumental variable technique to control for unmeasured confounding. The principal limitation is the lack of data on outcomes other than mortality, such as activities of daily living, mental health, and quality of life, which are clearly important in a disabling condition such as stroke but are not available in the Stroke Improvement National Audit Programme dataset. In addition, the data were provided by hospitals participating in a voluntary audit, and although we excluded hospitals submitting low numbers of patients, we cannot exclude differences in stroke ascertainment between hospitals. The dataset also does not contain the National Institutes of Health stroke severity score measure, which is widely used in stroke research. Instead the mortality model developed for this study uses five variables relating to stroke severity (consciousness level and four variables describing the extent of neurological deficit). However, despite the lack of the stroke severity score, the mortality model used in our study had similar discrimination to previously published models incorporating such a score ${ }^{22}$ (a C index of 0.858 
compared with 0.864 for the stroke severity score model) suggesting that the variables included in the model can provide a good approximation for stroke severity in models of stroke related mortality.

\section{Conclusion}

This study shows the associations between the organisational quality of stroke services, process of care, and 30 day mortality after stroke. Three of the individual process measures (including two care bundles) were associated with reduced mortality, and further studies are warranted to evaluate these in more detail. In addition, although the findings may still be influenced by residual confounding, we used several techniques to reduce indication bias and found that a measure of the overall quality of care is associated with mortality outcomes at 30 days. These findings have important implications for quality improvement in stroke services and also contribute more generally to the evidence base for quality measures in healthcare.

We thank all those who have contributed to the Stroke Improvement National Audit Programme and Sentinel Stroke Audits. The audits would not be possible without their hard work and dedication. We also thank the Intercollegiate Stroke Working Party (see supplementary file for list of members) for their guidance and work to support the audits, and Toby Prevost for his comments on the manuscript.

Contributors: BDB designed the study, carried out the analysis, and drafted the initial manuscript. SA and MR carried out statistical analysis and contributed to the drafting of the Methods and Results section. JC, AH, PJT, AGR, and CDAW contributed to drafting and editing the final manuscript and reviewing the results of the statistical analysis. AGR is the guarantor.

Funding: The Stroke Improvement National Audit Programme audit is commissioned by the Healthcare Quality Improvement Partnership on behalf of the Department of Health in England. The National Sentinel Stroke Audit 2010 was commissioned by the Healthcare Quality Improvement Partnership on behalf of the Department of Health in England. No specific funding from any source was sought for this study. The research was supported by the National Institute for Health Research Biomedical Research Centre based at Guy's and St Thomas' NHS Foundation Trust and King's College London. The views expressed are those of the author(s) and not necessarily those of the NHS, the National Institute for Health Research, or the Department of Health.

Competing interests: AGR is National Clinical Director of Stroke, NHS England. All authors have completed the ICMJE uniform disclosure form at www.icmje.org/coi_disclosure.pdf (available on request from the corresponding author) and declare: no support from any organisation for the submitted work; no financial relationships with any organisations that might have an interest in the submitted work in the previous three years; no other relationships or activities that could appear to have influenced the submitted work.

Ethical approval: Ethical approval of the Stroke Improvement National Audit Programme audit was granted by the Ethics and Confidentiality Committee of the National Information Governance Board. This included Section 251 (under the NHS Act 2006) approval to collect data without active patient consent and patients are able to request for any identifiable data to not be included. No patient identifiable information is collected in the National Sentinel Stroke Audit. Patients and patient representatives are involved in the design, reporting, and oversight of Stroke Improvement National Audit Programme and Sentinel. Further ethical approval was not sought.
Data sharing: No additional data available.

Department of Health: Progress in improving stroke care. National Audit Office, 2010.

2 National Clinical Guideline for Stroke, 4th edn. Intercollegiate Stroke Working Party. Royal College of Physicians, 2012.

3 Wardlaw JM, Murray V, Berge E, Del Zoppo G. Thrombolysis for acute ischaemic stroke. Stroke 2010;41:e445-6.

4 Alteplase for treating acute ischaemic stroke (TA 264). National Institute for Health and Clinical Excellence, 2012.

5 Stroke Unit Trialists' Collaboration. Collaborative systematic review of the randomised trials of organised inpatient (stroke unit) care after stroke. BMJ 1997;314:1151.

6 Saxena R, Koudstall PJ. Anticoagulants for preventing stroke in patients with non-rheumatic atrial fibrillation and a history of stroke or transient ischaemic attack. Cochrane Database Syst Rev 2004;(2):CD000185.

7 Sandercock PAG, Counsell C, Gubitz GJ, Tseng MC. Antiplatelet therapy for acute ischaemic stroke. Cochrane Database Syst Rev 2008;(3):CD000029.

8 Langhorne P, Taylor G, Murray G, Dennis M, Anderson C, Bautz-Holter E, et al. Early supported discharge services for stroke patients: a meta-analysis of individual patient's data. Lancet 2005;365:501-6.

9 Reeves MJ, Parker C, Fonarow GC, Smith EE, Schwamm LH. Development of stroke performance measures: definitions, methods and current measures. Stroke 2010;41:1573-8

10 Wiedmann S, Norrving B, Abilleira S, Asplund K, Dennis M, Hermanek P, et al. Variations in quality indicators of acute stroke care in 6 European Countries: the European Implementation Score Collaboration. Stroke 2011:43:458-63.

11 National stroke audits, Royal College of Physicians. 2012. www.rcplondon.ac.uk/resources/ national-sentinel-stroke-audit.

12 Mant J. Process versus outcome indicators in the assessment of quality of health care. Int J Qual Saf 2001;13:475-80.

13 Birkmeyer JD, Dimick JB, Birkmeyer NJ. Measuring the quality of surgical care: structure, process or outcomes? J Am Coll Surg 2004;198:626-32.

14 Parker C, Schwamm H, Fonarow GC, Smith EE, Reeves MJ. Stroke quality metrics: systematic reviews of the relationships to patient centred-outcomes and the impact of public reporting. Stroke 2012;43:155-62.

15 Medical Research Information Service. Information centre for health and social care. 2012. www.ic.nhs.uk/services/data-linkage-service.

16 Stroke Improvement National Audit Programme, Royal College of Physicians. 2012. www. rcplondon.ac.uk/resources/sinap-latest-results.

17 Bamford J, Sandercock P, Dennis M, Burn J, Warlow C. Classification and natural history of clinically identifiable subtypes of cerebral infarction. Lancet 1991;337:1521-6.

18 Austin PC. An introduction to propensity score methods for reducing the effects of confounding in observational studies. Multivariate Behav Res 2011;46:399-424.

19 Lilford R, Pronovost P. Using hospital mortality rates to judge hospital performance: a bad idea that just won't go away. BMJ 2010;340:c2016.

20 Aylin P, Bottle A, Jarman B. Monitoring mortality. BMJ 2008;338:b1745.

21 Shaihan DM, Wolf RE, lezzoni IE, Kirle L, Normand ST. Variability in the measurement of hospital-wide mortality rates. N Engl J Med 2010;363:2530-9.

22 Fonarow GC, Pan W, Saver JL, Smith EE, Reeves MJ, Broderick JP. Comparison of 3-day mortality models for profiling hospital performance in acute stroke with and without adjustment for stroke severity. JAMA 2012;308:257-64.

23 Werner RM, Bradlow ET. Relationship between Medicare's Hospital Compare performance Werner RM, Bradlow ET. Relationship between Medicare's
measures and mortality rates. JAMA 2006;296:2694-702.

24 Lee JS, Primack BA, Mor MK, Stone RA, Obrosky DS, Yealy DM, et al. Processes of care and outcomes for community-acquired pneumonia. Am J Med 2011;124:e9-17.

25 Nicholas LN, Osborne NH, Birkmeyer JD, Dimick JB. Hospital process compliance and surgical outcomes in Medicare beneficiaries. Arch Surg 2010;145:999-1004.

26 Mohamed MA, Mant J, Bentham L, Rafferty J. Comparing process of stroke care in highand low-mortality hospitals in the West Midlands, UK. Int J Qual Health Care 2005;17:31-6.

27 Ingeman A, Pedersen L, Hundborg HH, Petersen P, Zeilke S, Mainz J, et al. Quality of care and mortality among patients with stroke: a nationwide follow-up study. Med Care 2009;46:63-9.

28 Bravata DM, Wells CK, Lo SC, Nadeau SE, Melillo J, Chodkowski D, et al. Process of care associated with acute stroke outcomes. Arch Intern Med 2010;170:804-10.

29 Rowat A, Graham C, Dennis M. Dehydration in hospital-admitted stroke patients: detection, frequency and association. Stroke 2012;43:857-9.

30 Middleton S, McElduff P, Ward J, Grimshaw JM, Dale S, D-Este C, et al. Implementation of evidence-based treatment protocols to manage fever, hyperglycaemia, and swallowing dysfunction in acute stroke (QASC): a cluster randomised controlled trial. Lancet 2011;378:1699-706

31 Saposnik G, Fang J, O'Donnell M, Hachinski V, Kapral MK, Hill MD. Escalating levels of access to in-hospital care and stroke mortality. Stroke 2008;39:2522-30.

32 Xian Y, Holloway RG, Chan PS, Noyes K, Shah MN, Ting HH, et al. Association between stroke center hospitalization for acute ischaemic stroke and mortality. JAMA 2011:205:373-80.

33 Draft Methodology Report. Patient Centred Outcomes Research Institute, 2012.

34 Donabedian A. The quality of care. How can it be assessed? JAMA 1988;260:1743-8.

Accepted: 24 April 2013

\section{Cite this as: BMJ 2013;346:\{2827}

This is an Open Access article distributed in accordance with the Creative Commons Attribution Non Commercial (CC BY-NC 3.0) license, which permits others to distribute, remix, adapt, build upon this work non-commercially, and license their derivative works on different terms, provided the original work is properly cited and the use is non-commercial. See: http://creativecommons.org/licenses/by-nc/3.0/. 


\section{What is already known on this topic}

Current evidence that measures of stroke care quality are associated with patient outcomes is limited

\section{What this study adds}

Patients admitted to more organised stroke services (based on a score of their staffing, facilities, and service level) are more likely to receive high quality care defined by process measures of care quality

Patients receiving high quality care have a reduced risk of death in the 30 days following stroke, after adjusting for patient characteristics and controlling for selection bias

One care bundle of antiplatelet therapy, hydration, and nutrition was strongly associated with reduced mortality, suggesting that controlled studies of fluid therapy and nutrition in acute stroke are warranted

\section{Tables}

\begin{tabular}{|c|c|c|}
\hline Processes & No (\%) eligible & Proportion (\%) receiving care process \\
\hline Seen by a stroke consultant or associate specialist within 24 hours of admission & $36197(100)$ & $28016(77.4)$ \\
\hline Brain scan within 24 hours of admission & $36195(100)$ & $30838(85.2)$ \\
\hline Bundle 1: seen by nurse and one therapist within 24 hours and all relevant therapists within 72 hours & $31055(85.8)$ & $15621(50.3)$ \\
\hline Bundle 2: nutrition screening and formal swallow assessment within 72 hours where appropriate & $32564(89.9)$ & $27191(83.5)$ \\
\hline $\begin{array}{l}\text { Bundle 3: patient's first ward of admission was stroke unit and they arrived there within four hours of } \\
\text { hospital admission }\end{array}$ & 34007 (93.9) & $17990(52.9)$ \\
\hline $\begin{array}{l}\text { Bundle 4: patient given antiplatelet therapy where appropriate and had adequate fluid and nutrition for } \\
\text { first } 72 \text { hours }\end{array}$ & $34011(94.0)$ & $19930(58.6)$ \\
\hline \multicolumn{3}{|l|}{ Quality score: } \\
\hline $0-4$ & 25904 (71.6) & $13885(53.6)$ \\
\hline 5 or 6 & 25904 (71.6) & $12020(46.4)$ \\
\hline
\end{tabular}


Table 2| Characteristics of cohort. Values are numbers (percentages) of patients unless stated otherwise

\section{Characteristics}

Median (interquartile range) age (years)

Age (years):

\begin{tabular}{|c|c|}
\hline $18-64$ & $7924(21.9)$ \\
\hline $65-74$ & $7803(21.5)$ \\
\hline $75-84$ & $11440(31.6)$ \\
\hline$\geq 85$ & $9030(25.1)$ \\
\hline Women & $18474(51.0)$ \\
\hline Independent before stroke & $28376(78.4)$ \\
\hline Oxygen required within 24 hours & $6778(18.7)$ \\
\hline Reduced consciousness within 72 hours & $7953(22.0)$ \\
\hline \multicolumn{2}{|l|}{ Stroke type*: } \\
\hline Total anterior circulation infarct & $4425(12.2)$ \\
\hline Partial anterior circulation infarct & $21295(58.8)$ \\
\hline Lacunar infarct & $6177(17.1)$ \\
\hline Posterior circulation infarct & $3266(9.0)$ \\
\hline Out of hours admissiont & $17482(48.3)$ \\
\hline Median (interquartile range) onset to admission time (mins) & $475(105-1075)$ \\
\hline \multicolumn{2}{|l|}{ Admission to stroke unit or intensive care unit: } \\
\hline$<24$ hours of admission & $29561(81.7)$ \\
\hline$<72$ hours of admission & $26981(92.4)$ \\
\hline \multicolumn{2}{|l|}{ Mortality (days): } \\
\hline $0-3$ & $829(2.3)$ \\
\hline $0-7$ & $1703(4.7)$ \\
\hline $0-30$ & $4156(11.5)$ \\
\hline $0-30$ if quality score $0-4$ & $1311(9.6)$ \\
\hline $0-30$ if quality score 5 or 6 & $711(5.9)$ \\
\hline
\end{tabular}

*Definition according to Oxford Community Stroke Project.

†Admission from 6 pm-8 am, weekend or public holiday.

Patients with acute stroke $(n=36197)$

77 (66-84) 


\begin{tabular}{|c|c|c|c|c|c|c|}
\hline \multirow[b]{2}{*}{ Processes } & \multicolumn{2}{|c|}{ Univariable $(n=36037)$} & \multicolumn{2}{|c|}{ Multivariable* $(n=36037)$} & \multicolumn{2}{|c|}{$\begin{array}{c}\text { Multivariable*, excluding death or } \\
\text { palliative care in first } 3 \text { days }(n=27 \\
632)\end{array}$} \\
\hline & $\begin{array}{l}\text { Odds ratio }(95 \% \\
\text { Cl) }\end{array}$ & $P$ value & $\begin{array}{l}\text { Odds ratio }(95 \% \\
\text { Cl) }\end{array}$ & $P$ value & Odds ratio $(95 \% \mathrm{Cl})$ & $P$ value \\
\hline $\begin{array}{l}\text { Seen by a stroke consultant or } \\
\text { associate specialist within } 24 \\
\text { hours of admission }\end{array}$ & 0.77 (0.71 to 0.83$)$ & $<0.001$ & 0.88 (0.80 to 0.97$)$ & 0.009 & $0.86(0.78$ to 0.96$)$ & 0.007 \\
\hline $\begin{array}{l}\text { Brain scan within } 24 \text { hours of } \\
\text { admission }\end{array}$ & 0.89 (0.82 to 0.98$)$ & 0.01 & 0.96 (0.86 to 1.07 ) & 0.49 & 0.91 (0.81 to 1.04$)$ & 0.16 \\
\hline $\begin{array}{l}\text { Bundle 1: seen by nurse and one } \\
\text { therapist within } 24 \text { hours and all } \\
\text { relevant therapists within } 72 \text { hours }\end{array}$ & $0.82(0.76$ to 0.89$)$ & $<0.001$ & 0.90 (0.82 to 0.99$)$ & 0.028 & 0.91 (0.82 to 1.01$)$ & 0.089 \\
\hline $\begin{array}{l}\text { Bundle 2: nutrition screening and } \\
\text { formal swallow assessment within } \\
72 \text { hours where appropriate }\end{array}$ & $0.78(0.71$ to 0.86$)$ & $<0.001$ & 0.76 (0.67 to 0.87$)$ & $<0.0001$ & 0.83 (0.72 to 0.96$)$ & 0.01 \\
\hline $\begin{array}{l}\text { Bundle 3: patient's first ward of } \\
\text { admission was stroke unit and } \\
\text { they arrived there within four } \\
\text { hours of hospital admission }\end{array}$ & 0.96 (0.89 to 1.02$)$ & 0.19 & 0.99 (0.90 to 1.08$)$ & 0.75 & 0.95 (0.86 to 1.05$)$ & 0.31 \\
\hline $\begin{array}{l}\text { Bundle 4: patient given } \\
\text { antiplatelet therapy where } \\
\text { appropriate and had adequate } \\
\text { fluid and nutrition for first } 72 \text { hours }\end{array}$ & $0.24(0.22$ to 0.26$)$ & $<0.001$ & $0.46(0.42$ to 0.50$)$ & $<0.0001$ & 0.55 (0.49 to 0.61$)$ & $<0.001$ \\
\hline
\end{tabular}

*Adjusted for age, sex, independence in activities of daily living before stroke, requirement for oxygen therapy in first 24 hours, reduced consciousness in first 24 hours, arm weakness or sensory impairment, leg weakness or sensory impairment, dysphasia, hemianopia, and hospital level random effects. 
Table 4| Associations between quality score and 30 day mortality

\begin{tabular}{lcc} 
& \multicolumn{1}{c}{ Quality score $\mathbf{5}$ or $\mathbf{6}$ v $\mathbf{0 - 4}$} \\
\cline { 2 - 3 } Analyses (No of patients) & Odds ratio $(95 \%$ Cl) & P value \\
Univariable analysis $(n=25776)$ & $0.60(0.55$ to 0.66$)$ & $<0.001$ \\
\hline Multivariable analysis ${ }^{*}(n=25776)$ & $0.74(0.66$ to 0.83$)$ & $<0.001$ \\
\hline $\begin{array}{l}\text { Multivariable analysis }{ }^{*} \text { : excluding death or palliative care in } \\
\text { first } 72 \text { hours }(n=20457)\end{array}$ & $0.77(0.68$ to 0.88$)$ & $<0.001$ \\
\hline Instrumental variable analysis* $(n=25776)$ & $0.62(0.46$ to 0.83$)$ & 0.0001 \\
\hline
\end{tabular}

*Adjusted for age, sex, independence in activities of daily living before stroke, requirement for oxygen therapy in first 24 hours, reduced consciousness in first 24 hours, arm weakness or sensory impairment, leg weakness or sensory impairment, dysphasia, and hemianopia. 
Table 5| Standardised differences between levels of quality score and stroke service organisational score. Values are numbers (percentages) unless stated otherwise

\begin{tabular}{|c|c|c|c|c|c|c|}
\hline \multirow[b]{2}{*}{ Characteristics } & \multicolumn{2}{|c|}{ Quality score } & \multirow[b]{2}{*}{ Standardised difference ${ }^{\star}(\%)$} & \multicolumn{2}{|c|}{ Stroke service organisational score } & \multirow{2}{*}{$\begin{array}{c}\text { Standardised difference } \\
(\%)\end{array}$} \\
\hline & $0-4$ & 5 or 6 & & Below median & Above median & \\
\hline Mean (SD) age (years) & $75.1(13.2)$ & $73.5(13.4)$ & -12.1 & $74.7(13.4)$ & $73.9(13.7)$ & -6.0 \\
\hline Men & 48.0 & 50.8 & 5.6 & 48.1 & 50.2 & 4.2 \\
\hline Oxygen required in first 24 hours & 19.3 & 12.8 & -17.8 & 21.1 & 15.9 & -13.4 \\
\hline Out of hours admission & 53.8 & 46.8 & -14.0 & 46.5 & 50.5 & 8.0 \\
\hline Leg motor or sensory deficit & 58.8 & 63.1 & 8.8 & 61.1 & 64.2 & 6.4 \\
\hline Arm motor or sensory deficit & 67.3 & 73.6 & 13.8 & 70.0 & 73.0 & 6.6 \\
\hline Dysphasia & 48.0 & 45.4 & -5.2 & 49.6 & 45.0 & 9.2 \\
\hline Hemianopia & 21.4 & 22.6 & 2.9 & 23.3 & 26.2 & 6.7 \\
\hline Fully conscious in first 24 hours & 80.4 & 85.4 & 13.3 & 77.6 & 78.6 & 2.4 \\
\hline Independent before stroke & 77.4 & 83.8 & 16.2 & 77.1 & 80.0 & 7.1 \\
\hline \multicolumn{7}{|l|}{ Quality score: } \\
\hline $0-4$ & - & - & - & 65.7 & 37.6 & -58.6 \\
\hline 5 or 6 & - & - & - & 34.3 & 62.4 & 58.6 \\
\hline
\end{tabular}


Table 6 | Association between quarters of stroke service organisational score and $\mathbf{3 0}$ mortality, stratified by quality score

\begin{tabular}{|c|c|c|c|c|c|}
\hline \multirow[b]{3}{*}{ Quality score } & \multirow[b]{3}{*}{ No of patients } & \multicolumn{4}{|c|}{ Odds ratio for 30 day mortality ${ }^{*}(95 \% \mathrm{Cl})$} \\
\hline & & \multicolumn{4}{|c|}{ Quarters of stroke service organisational score } \\
\hline & & 1 (lowest $t$ ) & 2 & 3 & 4 (highest) \\
\hline $0-4$ & 13812 & 1.00 & $1.00(0.79$ to 1.27$)$ & 0.86 (0.66 to 1.12$)$ & $0.95(0.70$ to 1.29$)$ \\
\hline 5 or 6 & 11964 & 1.00 & 0.90 (0.66 to 1.22$)$ & $1.13(0.87$ to 1.67$)$ & $1.03(0.78$ to 1.36$)$ \\
\hline
\end{tabular}

*Estimated by fitting multilevel logistic regression models, with hospital level random intercepts. †Stroke services in bottom quarter of organisational score used as reference category. 


\section{Figures}

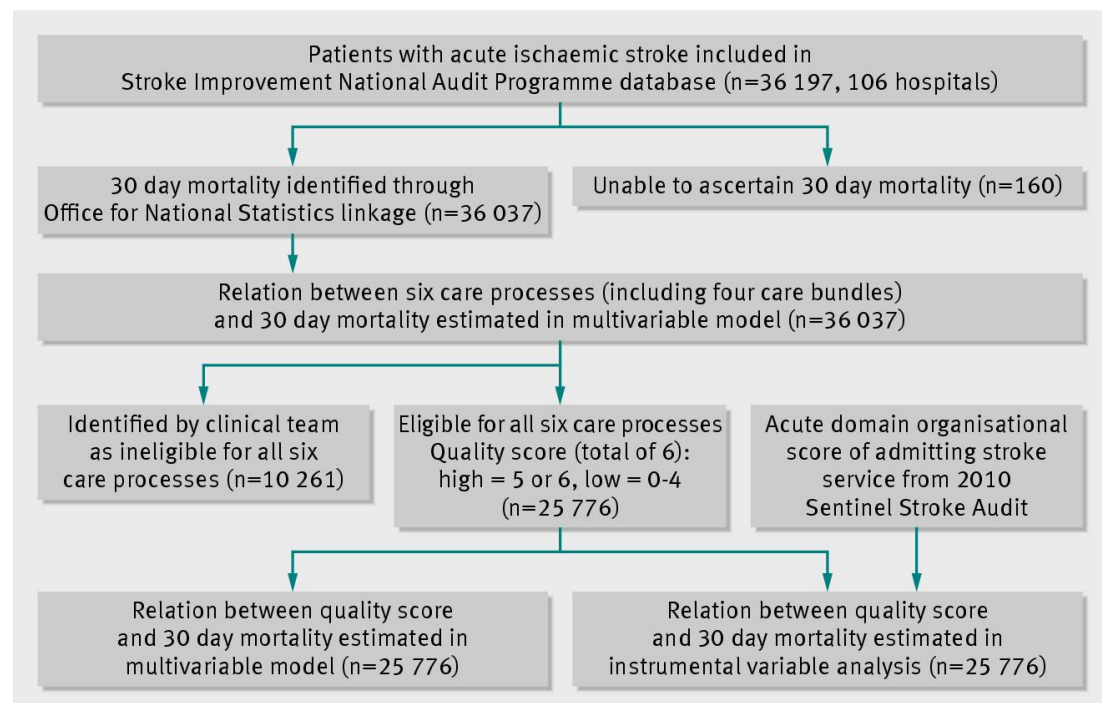

Fig 1 Study design

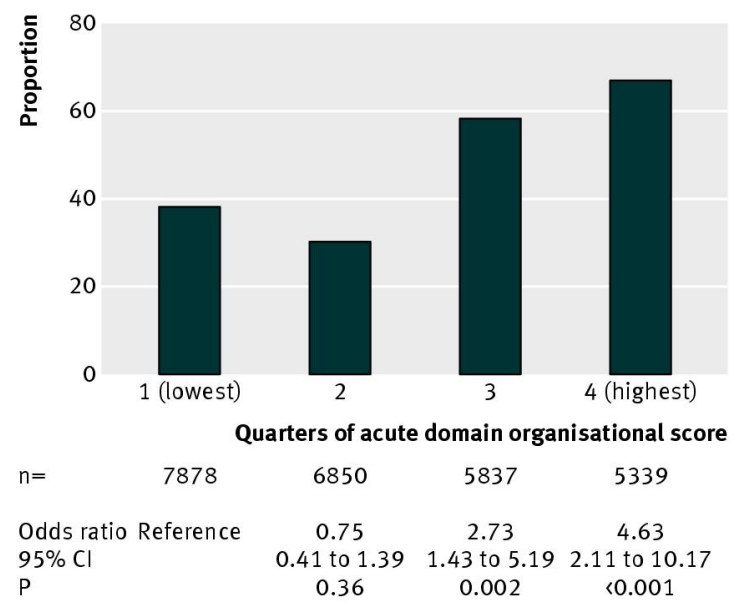

Fig 2 Proportion of patients with high quality score ( 5 or 6 of 6 ) by fourth of stroke service organisational score. Odds ratio of achieving 5 or 6 processes versus $0-4$ processes by fourth of stroke service organisational score, estimated in multilevel binary logistic model 